\title{
Penerapan Metode Fuzzy Mamdani Untuk Memprediksi Angka Penjualan Berdasarkan Persediaan Dan Jumlah Permintaan Pada Kilang Padi CV.Usaha Bersama
}

\author{
Hardianti Manurung ${ }^{1}$, Murni Marbun ${ }^{2}$ \\ ${ }^{1,2}$ STMIK Pelita Nusantara \\ Program Studi Teknik Informatika STMIK Pelita Nusantara \\ Jl. ST. Iskandar Muda No.1 Medan, Indonesia \\ Corresponding author's e-mail: hardiantimanurung@gmail.com
}

\begin{abstract}
Abstrak - Untuk dapat bersaing di dunia bisnis saat ini, industri kecil dalam manajemen harus terdepan dalam manajemen operasional dan sebagainya dari segi manajemen operasional salah satunya perusahaan harus meningkatkan efektifitas dan efesiensi operasional modern seperti perencanaan produksi,dan sebangainya. Kebutuhan akan informasi yang jelas,cepat dan efesien sangat penting mengingat bidang bisnis yang diangani CV.Usaha bersama merupakan kilang padi yang memasarkan serta memproduksi beras yang sehat dan higenis. Kilang padi CV.Usaha Bersama sering mengalami ketidakstabilan permintaan pasar terhadap produk beras yang terkadang tinggi dan rendah. Hal itu menjadi permasalahan bagi kilang padi CV.Usaha Bersama dalam menentukan perencanaan jumlah produksi, Dimana kilang padi CV.Usaha Bersama dalam pengelolaannya masih secara manual sehingga sangat tidak efektif dan tidak efesien. Proses pengerjaan laporan ini tentu saja memakan waktu sehingga dibutuhkan waktu yang lama dalam melakukan pemesanan dan menyebabkan adanya kekosongan stok persediaan pada gudang dan beras yang kurang diminati akan menjadi lama terjual. Hal ini mengakibatkan manajemen mengalami kesulitan sehingga proses penjualannya terganggu dan menggakibatkan perusahaan mengalamni kerugian. Untuk itu diperlukannya sebuah sistem pendukung keputusan dengan Metode Fuzzy Mamdani dalam memprediksi angka penjualan berdasarkan persediaan dan jumlah permintaan pada kilang padi cv.usaha bersama. Tempat riset pada penelitian ini dilakukan di cv.usaha bersama. Adapun yang menjadi variabel adalah permintaan, persediaan, dan penjualan. Hasil dari penelitian ini didapatkan jumlah prediksi penjualan beras ukuran $10 \mathrm{~kg}$ yang terjual untuk bulan April tahun 2021oleh CV.Usaha Bersama adalah 3184 karung. Metode Fuzzy Mamdani cukup efektif dalam memberikan keputusan yang optimal. Sistem ini dibangun dengan berbasis web dan MYSQL sebagai database.

Kata kunci : Fuzzy Mamdani, Persediaan, Penjualan, Beras, SPK
\end{abstract}

Abstract- To be able to compete in today's business world, small industries in management must be at the forefront of operational management and so on in terms of operational management, one of which companies must improve the effectiveness and efficiency of modern operations such as production planning, and so on. The need for clear, fast and efficient information is very important considering the business field handled by $C V$. Usaha Bersama is a rice factory that markets and produces healthy and hygienic rice. The CV.Usaha Bersama rice mill often experiences instability in market demand for rice products, which are sometimes high and low. This is a problem for the CV.Usaha Bersama rice mill in determining the amount of production planning, where the CV.Usaha Bersama rice mill is still being managed manually so it is very ineffective and inefficient. The process of working on this report, of course, takes time, so it takes a long time to place an order and causes vacancies in stock in warehouses and rice that is not in demand will take a long time to sell. This resulted in management experiencing difficulties so that the sales process was disrupted and resulted in the company experiencing losses. For this reason, a decision support system with the Fuzzy Mamdani method is needed in predicting sales figures based on supply and demand at the $\mathrm{cv}$. joint venture rice mill. The place of research in this study was carried out at CV. Usaha Bersama. The variables are demand, supply, and sales. The results of this study showed that the number of predictions of sales of $10 \mathrm{~kg}$ of rice sold for April 2021 by CV.Usaha Bersama was 3184 sacks. The Fuzzy Mamdani method is quite effective in providing optimal decisions. This system is built with web-based and MYSQL as database.

Keywords : Fuzzy Mamdani, Inventory, Sales, Rice, SPK.

\section{Pendahuluan}

Untuk dapat bersaing di dunia bisnis saat ini,industri kecil dalam manajemen harus terdepan dalam manajemen operasional dan sebagainya.dari segi manajemen operasional salah satunya perusahaan harus meningkatkan efektifitas dan efesiensi operasional modern seperti perencanaan produksi,dan sebangainya. Peranan informasi yang ditata dalam suatu struktur yang jelas,cepat,tepat,dan efesien akan sangat mendukung kelancaran operasional atau suatu oraganisasi. Demikian juga dengan CV.Usaha Bersama Tanjung Morawa, 
kebutuhan akan informasi yang jelas,cepat dan efesien sangat penting mengingat bidang bisnis yang diangani CV.Usaha bersama merupakan kilang padi yang memasarkan serta memproduksi beras yang sehat dan higenis.

Kilang padi CV.Usaha Bersama sering mengalami ketidakstabilan permintaan pasar terhadap produk beras yang terkadang tinggi dan rendah.Hal itu menjadi permasalahan bagi kilang padi CV.Usaha Bersama dalam menentukan perencanaan jumlah produksi, Dimana kilang padi CV.Usaha Bersama dalam pengelolaannya masih secara manual sehingga sangat tidak efektif dan tidak efesien. Proses pengerjaan laporan ini tentu saja memakan waktu sehingga dibutuhkan waktu yang lama dalam melakukan pemesanan dan menyebabkan adanya kekosongan stok persediaan pada gudang dan beras yang kurang diminati akan menjadi lama terjual.

Hal ini mengakibatkan manajemen mengalami kesulitan sehingga proses penjualannya terganggu dan menggakibatkan perusahaan mengalamni kerugian. Berdasarkan masalah yang sering terjadi,dibutuhkan system baruagar produksi beras tepat waktu dan dalam jumlah yang epat merupakan hal diinginkan oleh kilang padi CV.Usaha Bersama.Maka,permasalah tersebut perlu diselesaikan dengan merencanakan jumlah produksi,berdasrkan persediaan dan jumlah permintaan.

Metode Fuzzy Mamdani merupakan salah satu bagian dari Fuzzy Inference System yang berguna untuk penarikan kesimpulan atau suatu keputusan terbaik dalam permasalahan yang tidak pasti. Metode Fuzzy Mamdani diperkenalkan oleh Ebrahim Mamdani pada tahun 1975[1]. Proses pengambilan keputusan dengan menggunakan Metode Fuzzy Mamdani untuk memperoleh keputusan yang terbaik[2]. Dalam kasus ini peneliti melakukan salah satu cara yang bisa digunakan dalam memprediksi angka penjualan beras berdasarkan persediaan dan jumlah perminaan adalah penerapan meode fuzzy mamdani, karena terdapat beberapa data yang bisa digunakan dalam melakukan perhitungan guna mendapakan jumlah penjualan beras pada kilang padi CV.Usaha Bersama.

Berdasarkan penelitian terdahulu yaitu " penerapan metode fuzzy mamdani untuk memprediksi penjualan gula" penelitian ini menghasilkan $89,78 \%$ sehingga hal ini dianggap cocok dan sesuai oleh bagian penjualan.karena tingkat akurasinya yang masih cukup tinggi.Dari penelitian terdahulu dapat disimpulkan penggunaan metode fuzzy mamdani berhassil diterapkan dengan tingkat akurasi $89,78 \%$ dan sangat mendukung jika digunakan dalam penelitian ini.[3].

Proses pengerjaan laporan ini tentu saja memakan waktu sehingga dibutuhkan waktu yang lama dalam melakukan pemesanan dan menyebabkan adanya kekosongan stok pada toko dan produk yang kurang diminati menjadi lama terjual, hal ini mengakibatkan pihak menejemen kesulitan sehingga proses penjualan terganggu dan mengakibatkan perusahaan mengalami kerugian. Berdasarkan masalah yang terjadi, dibutuhkan sistem baru yang lebih mendukung dalam menyelesaikan transaksi untuk mengetahui jumlah stok produk herbal agar tidak mengalami permasalahan dalam stok penjualan. Salah satu cara yang bisa digunakan dalam menentukan jumlah stok produk adalah penerapan logika fuzzy Mamdani, karena terdapat beberapa data yang bisa digunakan dalam melakukan perhitungan guna mendapatkan jumlah stok produk[4].

\section{Tinjauan Pustaka}

\subsection{Sistem Pendukung Keputusan}

Sistem pendukung keputusan dapat diartikan sebagai suatu sistem yang dirancang yang digunakan untuk mendukung manajemen di dalam pengambilan keputusan[5]. Sistem pendukung keputusan adalah sekumpulan prosedur berbasis model untuk data pemrosesan dan penilaian guna membantu para manajer mengambil keputusan[6]. Sistem pendukung keputusan (Decision Support System) dirancang untuk memberikan informasi yang dapat membantu proses pengambilan keputusan dan kemampuan komunikasi untuk menjawab problem semi-terstruktur[7]. Little Turban menjelaskan bahwa,Sistem Pendukung Keputusan sebagai suatu informasi berbasis komputer yang menghasilkan berbagai alternative keputusan untuk membantu manajemen dalam menangani berbagai permasalahan yang terstruktur maupun tidak terstruktur dengan menggunakan data dan model[8]. Moore dan Chang berpendapat bahwa, Sistem Pendukung Keputusan dapat menangani situasi semistruktur dan tidak terstruktur)[9].

\subsection{Fuzzy Multiple Attribute Decision Making (FMADM)}

Fuzzy Multiple Attribute Decision Making (FMADM) adalah suatu metode yang digunakan untuk mencari alternatif optimal dari sejumlah alternatif dengan kriteria tertentu. Inti dari FMADM adalah menentukan nilai bobot untuk setiap atribut, kemudian dilanjutkan dengan proses perankingan yang akan menyeleksi alternatif yang sudah diberikan[10]. Pada dasarnya, ada 3 (tiga) pendekatan untuk mencari nilai bobot atribut, yaitu pendekatan subjektif, pendekatan objektif dan pendekatan integrasi antara subjektif dan objektif. Masingmasing pendekatan memiliki kelebihan dan kelemahan. Pada pendekatan subjektif, nilai bobot ditentukan berdasarkan subjektivitas dari para pengambil keputusan, sehingga beberapa faktor dalam proses perankingan alternatif bisa ditentukan secara bebas. Pada pendekatan objektif, nilai bobot dihitung secara matematis 
sehingga mengabaikan subyektivitas dari pengambil keputusan. Ada beberapa metode yang dapat digunakan untuk menyelesaikan masalah FMADM yaitu Simple Additive Weighting Method, Weighted Product (WP), ELECTRE, TOPSIS (Technique for Order Preference by Similarity to Ideal Solution) dan Analytic Hierarchy Process (AHP). (Hendharti,Taufiq, 2018:124).

Ada beberapa metode yang dapat digunakan untuk menyelesaikan masalah FMADM antara lain[11]:

1. Simple Additive Weighting Method.

2. Weighted Product (WP).

3. ELECTRE.

4. Technique for Order Preference by Similarity to Ideal Solution (TOPSIS).

Analytic Hierarchy Process (AHP).

\subsection{Metode Fuzzy Mamdani}

Metode mamdani adalah salah satu teknik inferensi fuzzy yang juga disebut dengan metode MaxMin.Metode ini diprkenalkan oleh Ebrahim Mamdani pada tahun 1975.Pada metode ini, terdapat 4 tahap untuk mendapatkan output, yaitu : Fuzzification, Rule Evaluation,Rule Agggregation,Defuzzification.

\subsection{Penjualan}

Penjualan merupakan aspek penting dalam perusaahan yang memperngaruhi keuntungan perusahaan. Jumlah penjualan yang sesuai dengan permintaan toko dan stok kemas yang ada di gudang tentunya akan mencapai target pasar yang telah ditentukan dan menaikkan potensi keuntungan perusahaan. Akan tetapi, dalam kenyataannya perhitungan dalam penjualan selalu dilakukan dengan manual sehingga mempengaruhi kebijakan perusahaan dalam penjualan. Sehingga, dibutuhkan suatu system yang dapat memprediksi jumlah produksi barang sesuai dengan permintaan dan persediaan Ningsih dkk., (2017). Oleh karena itu, kegiatan penjualan seperti halnya kegiatan penjualan seperti halnya kegiatan pembelian, terdiri dari serangkaian kegiatan yang meliputi penciptaan permintaan, menemukan si pembeli, nogosiasi harga, dan syarat-syarat pembayaran.dalam hal ini, penjualan ini, seperti penjual harus menentukan kebijaksanaan dan prosedur yang akan diikuti memungkinkan dilaksankannya rencana penjualan yang ditetapkan.

\section{Metode Penelitian}

Metode penelitian dapat dikatakan Kerangka kerja penelitian membahas tentang model pelaksanaan penelitian yang merupakan langkah-langkah untuk membahas tentang proses yang dilakukan dalam penyelesaian masalah penelitian. Tahap pada kerangka kerja penelitian ini digambarkan dengan alur penelitian dengan sebagai berikut:

Tahapan-tahapan dilakukan dengan mengikuti langkah-langkah sesuai dengan alur rancangan penelitian penulis sebagai berikut:

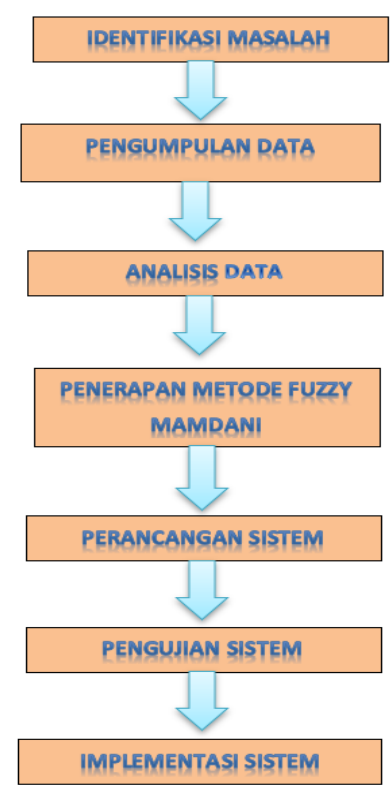

Gambar 1. Kerangka Kerja Penelitian 


\section{Hasil dan Pembahasan}

Langkah-langkah penyelesaiannya:

\subsection{Analisa Data}

Analisa data adalah teknik pengumpulan data penelitian .Tujuan dari langkah pengumpulan data dan teknik pengumpulan data ini adalah untuk mendapatkan data yang valid, sehingga hasil dan kesimpulan penelitian tidak akan diragukan kebenarannya. Kebutuhan data pada penelitian ini diperoleh dengan teknik observasi dan wawancara. Data yag dikumpulkan adalah data untuk memprediksi penjulan beras berdasarkan jumlah persediaan dan jumlah permintaan. Kilang padi CV. Usaha bersama pada dasarnya hanya memakai perhitungan penjualan beras secara manual. Penjualan dilakukan jika persediaan masih mencukupi kebutuhan konsumen. Berdasarkan dari sistem yang sedang berlangsung oleh karena itu sistem yang akan dibangun, yaitu dengan menerapkanMetode Fuzzy Mamdani untuk memudahkan pihak kilang padi CV. Usaha Bersama dalam prediksi jumlah penjualan beras berdasarkan persediaan dan jumlah permintaan. Berikut data penelitian yang dipakai untuk penelitian ini

Tabel 1. Data Penelitian

\begin{tabular}{|c|c|c|c|c|}
\hline Tahun & Bulan & Pemintaan Toko & Persediaan & Penjualan \\
\hline 2020 & Januari & 276 & 3210 & 2321 \\
\hline 2020 & Februari & 575 & 6435 & 4638 \\
\hline 2020 & Maret & 345 & 3851 & 3725 \\
\hline 2020 & April & 1035 & 7597 & 9321 \\
\hline 2020 & Mei & 575 & 7065 & 5678 \\
\hline 2020 & Juni & 690 & 4065 & 6660 \\
\hline 2020 & Juli & 896 & 8369 & 7623 \\
\hline 2020 & Agustus & 414 & 6590 & 3965 \\
\hline 2020 & September & 578 & 4320 & 4932 \\
\hline 2020 & Oktober & 869 & 7890 & 7995 \\
\hline 2020 & November & 996 & 12365 & 8960 \\
\hline 2020 & Desember & 1358 & 7896 & 10.321 \\
\hline 2021 & Januari & 598 & 5398 & 5908 \\
\hline 2021 & Februari & 437 & 3925 & 3788 \\
\hline 2021 & Maret & 620 & 4985 & 2785 \\
\hline 2021 & April & 568 & 5250 & $?$ \\
\hline
\end{tabular}

Langkah-langkah penerapan modeto Fuzzy Mamdani sebagai berikut:

\section{Pembentukan Himpunan Fuzzy}

Tahap pertama dari prosedur Metode Fuzzy Mamdani adalah pembentukan himpunan fuzzy atau dikenal pula dengan istilah fuzzifikasi. Fuzzifikasi merupakan proses yang dilakukan dengan mengtransformasi input himpunan tegas (crisp) ke dalam himpunan fuzzy.

a. Variabel Permintaan

Ada 3 variabel fuzzy Permintaan yang akan dimodelkan, yaitu: permintaan, persediaan, dan penjualan.

Variabel Permintaan terdiri dari 3 himpunan fuzzy yaitu:

BERKURANG $=[200,400,800]$

SEDANG $=[500,800,1100]$

BERTAMBAH $=[800,1200,1500]$

b. Variabel Persedian

Persediaan terdiri dari 3 himpunan fuzzy yaitu:

RENDAH $=[3000,5000,9000]$

TETAP $=[6000,9000,12000]$

TINGGI $=[9000,1300,15000]$

c. Variabel Penjualan

Penjualan terdiri dari 3 himpunan fuzzy yaitu:

RENDAH $=[200,600,800]$

SEDANG $=[600,800,1000]$

NAIK $=[800,1000,1200]$

\section{Aplikasi Fungsi Implikasi}

Tahap kedua dari prosedur Metode Fuzzy Mamdani adalah penerapan fungsi implikasi. Fungsi implikasi merupakan struktur logika yang terdiri atas kumpulan premis dan satu konklusi. Fungsi implikasi berguna untuk mengetahui hubungan antara premis-premis dan konklusinya. Bentuk dari fungsi implikasi ini adalah dengan pernyataan IF $\mathrm{x}$ is A THEN $\mathrm{y}$ is $\mathrm{B}$, dengan $\mathrm{x}$ dany adalah skalar, serta A dan B adalah himpunan fuzzy. Berdasarkan variable maka terdapat 9 fungsi implikasi yaitu: 
[R1] IF Permintaan BERKURANG And Persediaan RENDAH THEN Penjualan Beras RENDAH

[R2] IF Permintaan BERKURANG And Persediaan TETAP THEN Penjualan Beras SEDANG

[R3] IF Permintaan BERKURANG And Persediaan TINGGI THEN Penjualan Beras NAIK

[R4] IF Permintaan SEDANG And Persediaan RENDAH THEN Penjualan Beras RENDAH

[R5] IF PermintaanSEDANG And Persediaan TETAP THEN Penjualan Beras SEDANG

[R6] IF Permintaan SEDANG And Persediaan TINGGI THEN Penjualan Beras NAIK

[R7] IF PermintaanBERTAMBAH And Persediaan RENDAH THEN Penjualan Beras RENDAH

[R8] IF Permintaan BERTAMBAH And Persediaan TETAP THEN Pejualan Beras SEDANG

[R9] IF Permintaan BERTAMBAH And Persediaan TINGGITHEN Penjualan Beras NAIK

Berdasarkan 9 aturan fuzzy diatas, maka ditentukan nilai $\alpha$ dan z untuk masing-masing aturan. Langkahlangkah untuk mengkonversi 9 aturan tersebut sehingga diperoleh nilai dari $\alpha$ dari setiap aturan.

\section{Komposisi Aturan}

Tahap ketiga dari prosedur Metode Fuzzy Mamdani adalah komposisi aturan. Pada tahap ketiga ini, suatu prosedur dengan tujuan untuk menentukan inferensi dari kumpulan dan korelasi antar aturan menggunakan Metode Max, dengan makna lain yaitu prosedur menggabungkan fungsi keanggotaan dari aturanaplikasi fungsi implikasi.Solusi himpunan fuzzy diperoleh dengan cara mengambil nilai maksimum aturan, kemudian menggunakannya untuk memodifikasi daerah fuzzy dan mengaplikasikannya ke dalam output (keputusan akhir) dengan menggunakan operator OR (union).

Nilai maksimum dari aturan terdapat nilai $\mathrm{Z}$ pada penjualan $\mathrm{RENDAH}=0.58$, nilai $\mathrm{Z}$ pada penjualan $S E D A N G=0$ dan nilai $Z$ pada penjualan $N A I K=0$

Komposisi untuk $\mathrm{Z}$ penjualan $\mathrm{RENDAH}=0.58$ adalah:

$$
\begin{aligned}
& \frac{8000-z 1}{2000}=0.58 \\
& 8000-z 1=0.58(2000) \\
& 8000-z 1=1160 \\
& z 1=8000-1160 \\
& z 1=6840
\end{aligned}
$$

Komposisi untuk $\mathrm{Z}$ penjualan $\mathrm{SEDANG}=0$ adalah:

$\frac{z 2-6000}{2000}=0$

$z 2-6000=0$

$z 2=6000$

Komposisi untuk $\mathrm{Z}$ penjualan $\mathrm{SEDANG}=0$ adalah:

$\frac{10000-z 3}{2000}=0$
$10000-z 3=0$

$z 3=10000$

Komposisi untuk $\mathrm{Z}$ penjualan NAIK $=0$ adalah:

$\frac{z 4-8000}{2000}=0$

$z 4-8000=0$

$z 4=8000$

\section{Deffuzzyfikasi}

Tahap terakhir dari prosedur Metode Fuzzy Mamdani adalah proses defuzzifikasi. Proses defuzzifikasi dipergunakan untuk menafsirkan nilai keanggotaan fuzzy menjadi keputusan tertentu atau bilangan crips. Prosedur defuzzifikasi dengan menggunakan Metode Centroid, yaitu menentukan moment (integral dari masing-masing fungsi keanggotaan dari komposisi aturan), menentukan luas, dan menentukan titik pusat. Momen daerah I (M1)

Momen daerah II (M2)

$$
\begin{gathered}
=\int_{2000}^{6840} 0.58 z d z=\frac{0.58}{2} z^{2} \mid \begin{array}{l}
6840 \\
2000
\end{array} \\
=0.29\left(6840^{2}-2000^{2}\right) \\
=0.29(46785600-4000000) \\
=0.29(42785600) \\
=12407824
\end{gathered}
$$


$=\int_{6840}^{8000}\left[\frac{8000-z}{2000}\right] z d z$

$=\int_{6840}^{8000} 4 z-0.0005 z^{2} d z$

$=2 z^{2}-\left.0.000167 z^{3}\right|_{6840} ^{8000}$

$=\left[2\left(8000^{2}-6840^{2}\right)-0.000167\left(8000^{3}-6840^{3}\right)\right]$

$=[34428800-32061744.83]$

$=2367055.168$

Luas daerah I

$$
=3967.2
$$

$$
A 1=0.58(6840)
$$

Luas daerah II

$$
\begin{aligned}
A 2 & =0.58(8000-6840) \\
& =0.58(1160) \\
& =672.8
\end{aligned}
$$

Berdasarkan perhitungan momen dan luas daerah I dan II maka diperoleh titik pusat fuzzy yaitu:

$$
Z=\frac{M 1+M 2}{A 1+A 2}
$$

$Z=\frac{12407824+2367055.168}{3967.2+672.8}$

$Z=\frac{14774879.2}{4640}$

$Z=3184.241=3184$

Jadi, jumlah prediksi penjualan beras ukuran $10 \mathrm{~kg}$ yang terjual untuk bulan April tahun 2021oleh CV.Usaha Bersama adalah 3184 karung.

\section{Implementasi Sistem}

Tahap implementasi sistem merupakan tahap berdasarkan pada hasil analisa dan perancangan sebelumnya yang dimasukkan ke dalam suatu bentuk bahasa pemrograman pada komputer untuk diolah, kemudian komputer menjalankan fungsi-fungsi yang telah didefenisikan. Implementasi sistem dilakukan sebagai wujud nyata dari hasil analisia dan perancangan yang dilakukan sebelumnya oleh peneliti kedalam bahasa pemrograman untuk diterapkan pada keadaan yang sesungguhnya. Adapun kebutuhan-kebutuhan dari sistem yang harus disiapkan sebelum diimplementasikan yaitu kebutuhan perangkat lunak (software) dan perangkat keras (hardware).

\section{a.Form Login}

Form login merupakan halaman yang ditampilkan pertama kali pada saat sistem dijalankan oleh pengguna untuk masuk kedalam sistem. Pengguna memasukkan username dan password yang telah disediakan didalam database. Jika benar maka sistem akan menampilkan menu utama, sedangkan jika salah maka sistem akan menolak. Gambar form login dapat dilihat pada gambar 2.

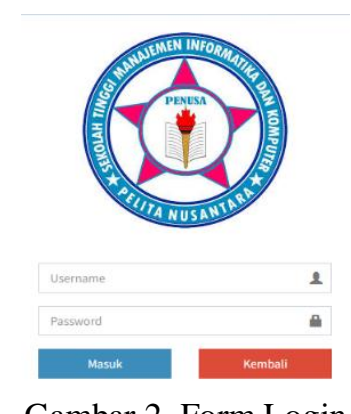

Gambar 2. Form Login

Form utama merupakan halaman yang ditampilkan setelah pengguna berhasil melakukan login. Form utama berisi halaman utama pada sistem dan menu-menu yang dapat digunakan oleh pihak pengguna.

Pada form utama terdapat beberapa menu, diantaranya: 


\section{b.Form Algoritma}

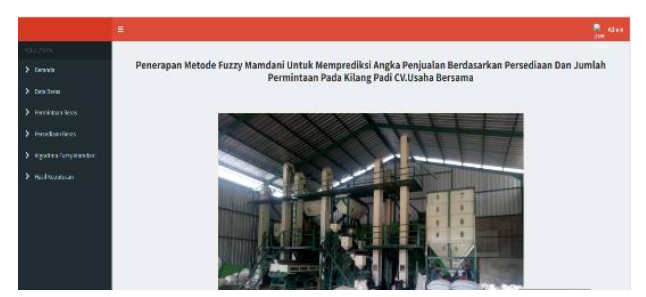

Gambar 3. Menu Utama

Form ini merupakan halaman yang digunakan untuk menampilkan hasil dari proses perhitungan algoritma Fuzzy Mamdani Hasil yang ditampilkan merupakan perhitungan antara fuzzy kriteria dengan bobotnya. Gambar form perhitungan dapat dilihat pada gambar 4.

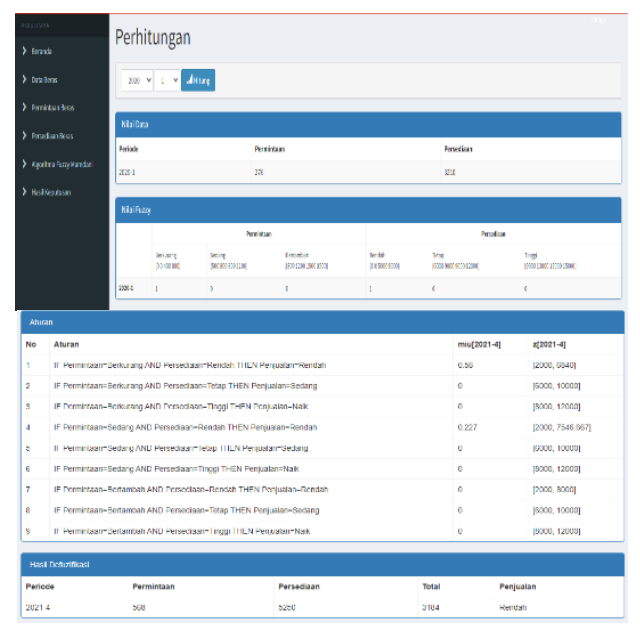

Gambar 4.Proses Keputusan

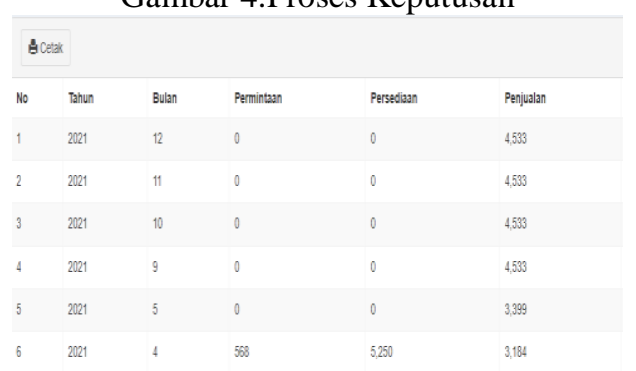

Gambar 5. Proses Keputusan

Jadi, jumlah prediksi penjualan beras ukuran $10 \mathrm{~kg}$ yang terjual untuk bulan April tahun 2021oleh CV.Usaha Bersama adalah 3184 karung.

\section{Kelemahan dan Kelebihan Sistem}

Kelebihan dari sistem ini adalah:

1. Program ini dapat dipakai oleh pihak riset dalam dalam melakukan analisa untuk memprediksi jumlah permintaan dan persediaan beras.

2. Program ini dapat menghasilkan analisa dengan akurasi yang cukup tinggi.

3. Implementasi dari metode fuzzy mamdani cukup efektif dalam membantu didalam proses pengambilan keputusan.

Kelemahan dari sistem ini adalah:

1. Program ini tidak dapat melakukan pembaharuan secara otomatis. Harus diinstall langsung pada komputer apabila ada yang mau diperbaharui.

2. Ruang lingkup sistem ini hanya untuk jumlah permintaan dan persediaan beras dalam jumlah yang tidak banyak.

3. Program ini belum berbasis website. 


\section{Kesimpulan Dan Saran}

Setelah melakukan berbagai macam tahapan-tahapan maka diperoleh suatu kesimpulan sebagai berikut:

1. Dengan menggunakan sistem ini, pihak tempat riset dapat terbantu.

2. Hasil keputusan pada penelitian ini cukup efektif karena memiliki tingkat akurasi yang tinggi.

3. Jumlah prediksi penjualan beras ukuran $10 \mathrm{~kg}$ yang terjual untuk bulan April tahun 2021 oleh CV.Usaha Bersama adalah 3184 karung.

4. Dengan menggunakan sistem logika fuzzy mamdani didalam prediksi jumlah permintaan dan persediaan beras, pengguna dapat menampilkan hasil prediksi dengan efektif terbaik dengan menggunakan PHP dan MySQL.

5. Sistem ini dapat membantu dan menjadi referensi bagi pihak riset.

Adapun saran-saran yang dapat disampaikan kepada pembaca, kepada pihak pengguna dan kepada seluruh pihak yang berkaitan dengan hasil penelitian ini, yaitu :

1. Bagi pihak kampus dapat memberikan support lebih baik lagi agar kualitas hasil penelitian dapat meningkat kedepannya.

2. Bagi pihak penelitian, diharapkan agar pegawai yang mengoperasikan aplikasi ini diberikan pelatihan singkat agar tidak terjadi kesalahan dalam penginputan datanya.

3. Bagi mahasiswa diharapkan agar melanjutkan penelitian ini sehingga sistem pendukung keputusan ini dapat kembangkan lagi, terutama dalam segi fitur dan interface-nya. Supaya lebih menarik tampilannya dan lebih mudah dipakai.

4. Bagi mahasiswa agar penelitian ini disempurnakan kedepannya dengan menambah metode atau kombinasi metode agar mendapatkan tingkat akurasi yang cukup tinggi.

5. Bagi mahaiswa agar sistem ini dibuat secara online dan interface-nya dapat kembangkan lagi.

\section{Daftar Pustaka}

[1] S. Susmanto, Z. Zulfan, and M. Munawir, "Sistem Penerapan Fuzzy Multi Attribute Decision Making (MADM) Dalam Mendukung Keputusan Untuk Menentukan Lulusan Terbaik Pada Sekolah Tinggi Teknik Poliprofesi Medan,” J. Nas. Komputasi dan Teknol. Inf., vol. 1, no. 1, 2018.

[2] H. A. Prasetyo, "Sistem Pendukung Keputusan Menentukan Produsen Terbaik Dalam Pembuatan Kerudung Pada CV. Hazna Indonesia Menggunakan AHP (Analytical Hierarchy Process) dan WP (Weighted Product)," Semnasteknomedia Online, vol. 5, pp. 13-18, 2017.

[3] N. Ningsih, N. T. Pambudi, and A. M. Abadi, "Penerapan Metode Fuzzy Mamdani untuk Memprediksi Penjualan Gula," Semin. Mat. Dan Pendidik. Mat. Uny, pp. 153-160, 2017.

[4] A. H. Nasyuha, M. Hutasuhut, and M. Ramadhan, "Penerapan Metode Fuzzy Mamdani Untuk Menentukan Stok Produk Herbal Berdasarkan Permintaan dan Penjualan," J. Media Inform. Budidarma, vol. 3, no. 4, p. 313, 2019.

[5] M. S. Grezan, "Sistem Pendukung Keputusan Pemilihan Motif Batik Solo Dengan Metode AHP," Sist. Pendukung Keputusan Pemilihan Motif Batik Solo Dengan Metod. AHP, pp. 1-19, 2016.

[6] N. Evy Sophia, Indah Mumpuni, "Pendahuluan Metode Promethee SPK Sistem Pendukung Keputusan," J. Ilm. Komputasi, vol. 19, no. 2, pp. 265-278, 2020.

[7] M. A. H. P. K-means, "Sistem Pendukung Keputusan Penerima Bantuan Langsung Tunai Tepat Sasaran Menggunakan," vol. 3, no. 2, pp. 45-54, 2020.

[8] W. Hutahaean and P. S. Hasugian, "Sistem Pendukung Keputusan Penentuan Penerima Bantuan Bedah Rumah Menggunakan Metode Weighted Product Pada Kecamatan Borbor," J. Nas. Komputasi dan Teknol. Inf., vol. 4, no. 1, 2021.

[9] E. L. Damanik and R. M. Simanjorang, "Sistem Pendukung Keputusan Menentukan Pemutusan Hubungan Kerja Karyawan CV. Biring Ndu Cahaya Panglong Dengan Metode AHP," J. Nas. Komputasi dan Teknol. Inf., vol. 4, no. 1, pp. 7-13, 2021.

[10] A. E. Silitonga and A. Simangunsong, "Sistem Pendukung Keputusan Dalam Menentukan Penerima Bantuan Langsung Tunai Dengan Metode Profile Matching Pada Kantor Kepala Desa Narigunung 1," J. Nas. Komputasi dan Teknol. Inf., vol. 3, no. 3, pp. 275-280, 2020.

[11] B. G. Ginting and F. A. Sianturi, "Sistem Pendukung Keputusan Pemberian Bantuan Kepada Keluarga Kurang Mampu Menggunakan Metode AHP," J. Nas. Komputasi dan Teknol. Inf., vol. 4, no. 1, 2021. 